\title{
Optimization of Friction Stir Spot Welding Process
}

Parameters using Taguchi's Approach

A.Belashher, E.H.Hamza, A.M.Gaafer,T.S.Mahmoud

Mechanical Engineering Dept., Faculty of Engineering, Shoubra, Benha Univ., Egypt

E-Mail:tamer.abdelmagid@feng.bu.edu.eg

\begin{abstract}
In the present investigation, friction stir spot welding (FSSW) on AA2024_T6 aluminum alloy plates was performed. The influences of the tool rotational speed, dwell time, plunge depth and plunge rate on tensile-shear load of welds were evaluated. The process parameters were optimized by Taguchi technique based on Taguchi's $\mathrm{L}_{9}$ orthogonal array. The optimum FSSW process parameters were predicted and their percentage of contribution was estimated by applying the signal-to-noise ratio and analysis of variance. The experimental results showed that the optimal levels of the rotational speed, plunge depth, plunge rate and dwell time were found to be $2 \circ 00$ $\mathrm{rpm}, 1.5 \mathrm{~mm}, 10 \mathrm{~mm} / \mathrm{min}$ and 10 seconds, respectively. The analysis of variance (ANOVA) results showed that the rotational speed is the most influential FSSW process parameter on the tensile-shear load with a percentage of contribution of $66.69 \%$ of the overall response. The plunge depth, plunge rate and dwell time FSSW process parameters showed percentage of contribution of $27 \%, 4 \%$ and $3 \%$, respectively, of the overall response.
\end{abstract}

Keywords: Optimization, Friction stir, Spot welding, Taguchi's approach.

\section{Introduction}

Alloy 2024 was introduced in 1931 as an aluminum clad sheet in the $\mathrm{T} 3$ temper. It was the first $\mathrm{Al}-\mathrm{Cu}-\mathrm{Mg}$ alloy to have a yield strength approaching 50,000 psi and generally replaced 2017-T4 (Duralumin) as predominant 2XXX series aircraft alloy. With its relatively good fatigue resistance, especially in thick plate forms, alloy 2024 continues to be specified for many aerospace structural applications such as in fuselage structural, wing tension members, shear webs and ribs and structural areas where stiffness, fatigue performance and good strength are required [1].

Friction stir welding (FSW) is a solid state joining process developed by the welding Institute (TWI) in 1991. The process combines frictional heating and plastic deformation to obtain high quality joint free from defects. The main advantage of the friction stir welding is that the temperature during is welding is less than the melting temperature of the work pieces, thus the deformation is significantly less than conventional arc welding technique. The main difference Friction stir spot (FSSW) and FSW is the rotating tool. In FSSW, a non- consumable rotating tool is plunged into the work pieces to be jointed. Upon reaching the desired plunge depth, the rotation tool is held in that position for a pre-determined finite time [2].

The effect of tool rotational speed on tensileshear strength is investigated by many researchers [3-8]. Optimization of FSSW process parameters for AA2198-T8 Sheets was studied by Pieta et al. [3]. Three different rotational speeds (1500, 2000 and $2500 \mathrm{rpm}$ ), plunge depths (3.7, 4.2, and 4.7 $\mathrm{mm})$ and dwell times $(4,7$, and $10 \mathrm{sec}$.) were used in their experiments. They found that with increasing tool rotational speed, lap shear strength increases and then tensile-shear strength decreases with increase in rotational speed. Saleh et al. [4] studied the effect of FSSW process parameters on the tensile-shear load of AA6061- T4 aluminum plates. FSSW was carried out at different tool rotational speeds (1000, 1500 and $2000 \mathrm{rpm})$, plunge depths $(0.5,0.7$, and $0.9 \mathrm{~mm})$, plunge rates $(10,20$, and $30 \mathrm{~mm} / \mathrm{min})$ and dwell times $(4,6$, and $8 \mathrm{sec}$.). The experimental results showed that the optimal levels of the rotational speed, plunge depth, plunge rate and dwell time were found to be 2000 $\mathrm{rpm}, \quad 0.9 \mathrm{~mm}, 10 \mathrm{~mm} / \mathrm{min}$ and 8 seconds, respectively. The rotational speed, plunge rate and dwell time FSSW process parameters showed percentage of contribution of $17 \%, 5 \%$ and $23 \%$, respectively, of the overall response. Application of Taguchi approach to optimize of FSSW parameters on joint properties of dissimilar AA2024-T3 and AA5754-H22 aluminum alloys was carried out by Yahiya et al. [6]. They found that with increasing plunge depth, the lap-shear strength increases.

The aim of the present investigation is to study the significance of the influence of the process parameters, mainly, the tool rotational speed, plunge depth, plunge rate and dwell time on the tensile-shear strength of AA2024-T6 plates joined using FSSW. The Taguchi's approach was applied to find out the optimum settings for each FSSW process parameters to achieve the maximum tensile-shear load for the welded AA2024-T6 plates.

\section{Experimental procedures \\ 2.1 Materials}

The present investigation, aluminum AA2024-T6 plates were joined using FSSW. The AA2024-T6 
plates have $3.5 \mathrm{~mm}$ thick. The chemical composition of the AA2024 is given in Table (1) .

\subsection{FSSW process}

The FSSW of AA2024-T6 plates was performed using CNC milling machine. Before welding, the sheets were cleaned with acetone to remove the oil and dirt impurities from the surface. Fig (1) illustrates the FSSW process carried out in the present study. The FSSW was carried out using a hardened H13 steel tool with a nominal chemical composition (wt.-\%) $0.39 \% \mathrm{C}, 0.40 \% \mathrm{Mn}, 5.2 \% \mathrm{Cr}$, $0.95 \% \mathrm{~V}, 1.4 \% \mathrm{Mo}, 1.10 \% \mathrm{Si}$, and $90.56 \% \mathrm{Fe}$. The tool has a straight cylindrical pin with $6 \mathrm{~mm}$ diameter and $4.5 \mathrm{~mm}$ length, and a shoulder of 24 $\mathrm{mm}$.

Table (1) The chemical composition of the AA2024 aluminum alloy

\begin{tabular}{ccccccccccc}
\hline Element & $\mathbf{A l}$ & $\mathbf{C r}$ & $\mathbf{C u}$ & $\mathbf{F e}$ & $\mathbf{M g}$ & $\mathbf{M n}$ & $\mathbf{S i}$ & $\mathbf{T i}$ & $\mathbf{Z n}$ & Other \\
\hline (wt.-\%) & 94.90 & 0.01 & 4.30 & - & 0.10 & 0.35 & 0.08 & 0.06 & 0.011 & 0.189 \\
\hline
\end{tabular}

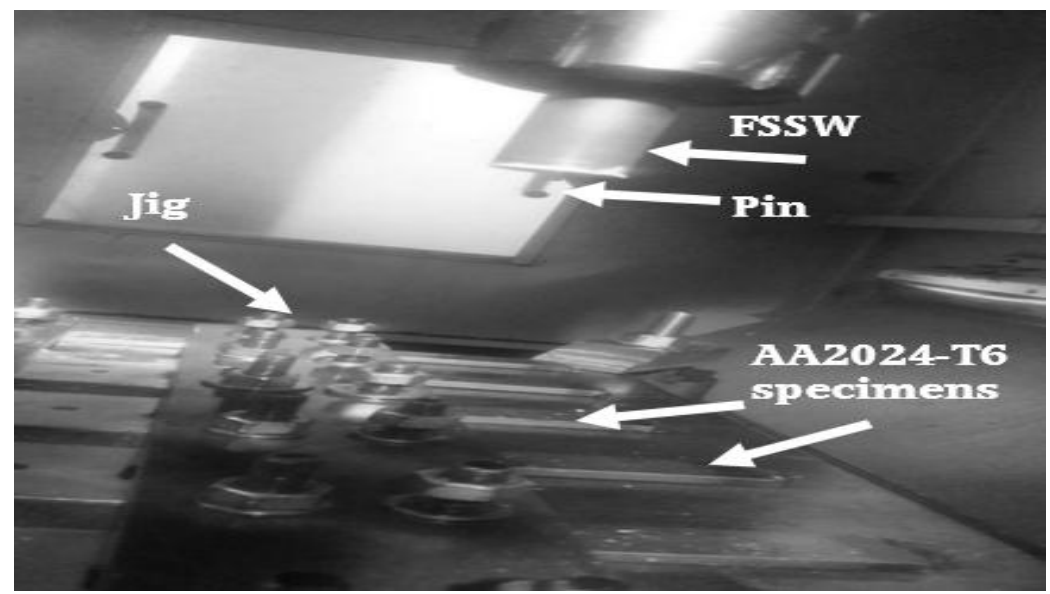

Fig (1) The FSSW setup used in the present work

\subsection{Tensile-shear test}

Tensile-shear tests were carried out to evaluate the performance of the welds. Lap-shear specimens according to DIN EN-ISO 14273 were made using two $50 \times 170 \mathrm{~mm}$ coupons with $3-\mathrm{mm}$ thickness and a $50 \times 50$ mm overlap area as shown in Fig (2), at which the FSSW was performed at its center. Tensile-shear tests were carried out at ambient temperature using a universal testing machine with a constant crosshead speed of $1 \mathrm{~mm} / \mathrm{min}$. From each condition, three tensile samples were tested.

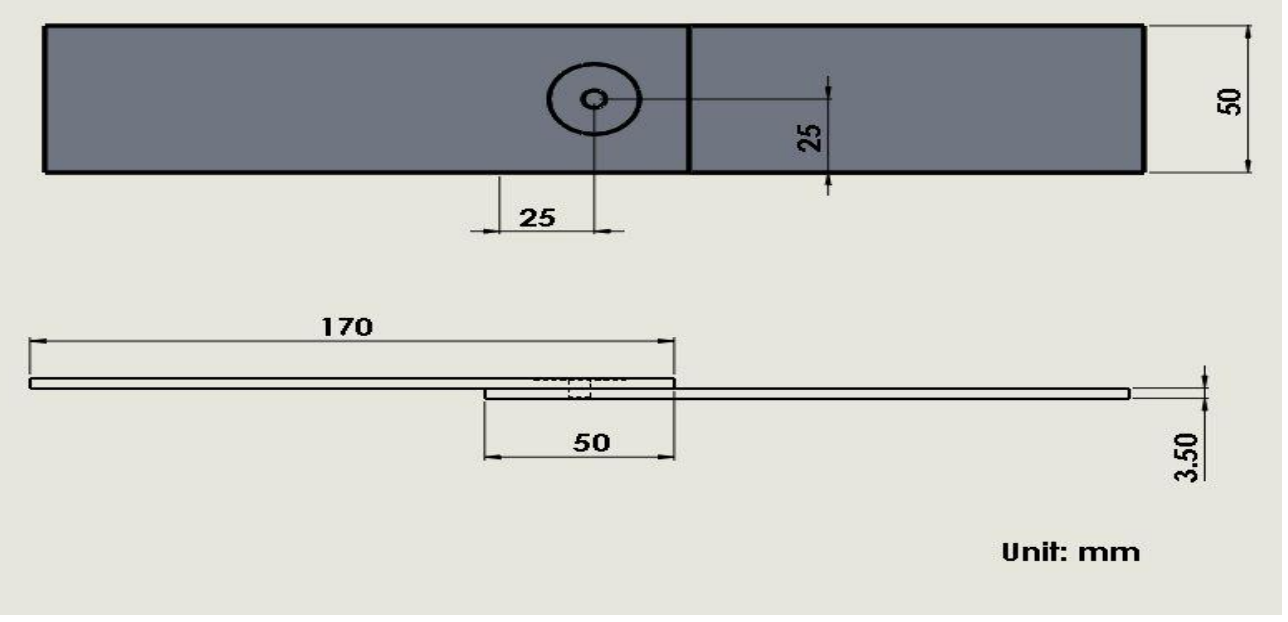

Fig (2) The tensile-shear specimen. (Dimensions in mm) 
In the present investigation, the influence of FSSW process parameters, typically, the too rotational speed, dwell time, the plunge rate and plunge depth on the tensile-shear strength of AA2024-T6 aluminum lap joints was evaluated. The FSSW process parameters were selected in three levels. Table 2 lists the FSSW process parameters and their levels. The design of experiments (DOE) was carried out using Taguchi's approach. The Taguchi's Orthogonal Array DOE was employed in order to study the effect of the aforementioned FSSW process parameters on the response (i.e. tensile-shear strength). Before selection of the orthogonal array (OA) particular, the number of factors and interactions of interest and the number of levels and interactions of interest must be considered. As three levels and four factors are taken into consideration, $\mathrm{L}_{9} \mathrm{OA}$ is used in this investigation. Table 3 lists the matrix of the $\mathrm{L}_{9}$ orthogonal array.

The signal to noise $\mathrm{S} / \mathrm{N}$ ratio was calculated based on the quality of characteristics intended. The signal-to-noise $(\mathrm{S} / \mathrm{N})$ ratio indicates the control factors just that minimize the effects of the noise factors. The main objective function described in this investigation is the maximization of the tensile shear strength, so the larger the best $\mathrm{S} / \mathrm{N}$ ratio was calculated. The formula for $\mathrm{S} / \mathrm{N}$ ratio is given below: -

$\eta=-10 \log 10 \frac{1}{n} \sum_{\mathrm{i}=1}^{n} \frac{1}{y_{\mathrm{i}}^{2}}$

Table (2) The FSSW process parameters and their levels

\begin{tabular}{lcccc}
\hline \multicolumn{1}{c}{ Parameter } & Unit & Level 1 & Level 2 & Level 3 \\
\hline Rotational speed & $(\mathrm{rpm})$ & 1500 & 2000 & 2500 \\
Plunge depth & $(\mathrm{mm})$ & 1.00 & 1.25 & 1.5 \\
Plunge rate & $(\mathrm{mm} / \mathrm{min})$ & 5 & 10 & 15 \\
Dwell time & $(\mathrm{s})$ & 8 & 10 & 12 \\
\hline
\end{tabular}

Table (3) The matrixof L9 orthogonal array

\begin{tabular}{lllll}
\hline RUN\# & Rotational & Plunge & Plunge & Dwell \\
& Speed $(\mathrm{rpm})$ & Depth $(\mathrm{mm})$ & Rate $(\mathrm{mm} / \mathrm{min})$ & time $(\mathrm{s})$ \\
\hline 1 & 1 & 1 & 1 & 1 \\
2 & 1 & 2 & 2 & 2 \\
3 & 1 & 3 & 3 & 3 \\
4 & 2 & 1 & 2 & 3 \\
5 & 2 & 2 & 3 & 1 \\
6 & 2 & 3 & 1 & 2 \\
7 & 3 & 1 & 3 & 2 \\
8 & 3 & 2 & 1 & 3 \\
9 & 3 & 3 & 2 & 1
\end{tabular}

Where $n$ is number of experiments and $y$ is observed response value. The Analysis of variance (ANOVA) test was performed to determine the influence and relative importance of the FSSW process parameters. The purpose of the ANOVA test is to investigate the significance of the FSSW process parameters which affect the tensile shear strength of AA2024-T6 lap joints. The design of experiments, $\mathrm{S} / \mathrm{N}$ and ANOVA calculations were performed using Minitab commercial statistical software.

\section{Results and discussion}

The results of the means and signal-to-noise $(\mathrm{S} / \mathrm{N})$ ratio for the tensile-shear strength are given in Table 4. The main effects of average mean and S/N ratio values of all levels are calculated and listed in Table 5 and 6 respectively. It is clear that a larger $\mathrm{S} / \mathrm{N}$ ratio corresponds to better quality 
characteristics. Therefore, the optimal level of process parameter is the level of highest $\mathrm{S} / \mathrm{N}$ ratio. Based on both mean and $\mathrm{S} / \mathrm{N}$ ratio, the optimal levels of tensile shear strength at rotational speed, plunge depth, plunge rate and dwell times are level
$3,3,1$ and 3 (2500 rpm, $1.5 \mathrm{~mm}, 10 \mathrm{~mm} / \mathrm{min}$ and $10 \mathrm{sec})$, respectively, as shown in graph and Fig $(3,4)$.

Table (4) The means and signal-to-noise $(\mathrm{S} / \mathrm{N})$ ratio for tensile-shear strength

\begin{tabular}{lcccccccc}
\hline $\begin{array}{l}\text { Rotational } \\
\text { Speed } \\
(\mathbf{r p m})\end{array}$ & $\begin{array}{c}\text { Plunge } \\
\text { Depth } \\
(\mathbf{m m})\end{array}$ & $\begin{array}{c}\text { Plunge } \\
\text { Rate } \\
(\mathbf{m m} / \mathbf{s})\end{array}$ & $\begin{array}{c}\text { Dwell } \\
\text { Time } \\
(\mathbf{s})\end{array}$ & $\begin{array}{c}\text { Sample } \\
\mathbf{( 1 )}\end{array}$ & $\begin{array}{c}\text { Sample } \\
\mathbf{( 2 )}\end{array}$ & $\begin{array}{c}\text { Sample } \\
\mathbf{( 3 )}\end{array}$ & S/N ratio & Mean \\
\hline 1500 & 1.00 & 5 & 8 & 2.60 & 2.55 & 2.55 & 8.1863 & 2.56667 \\
1500 & 1.25 & 10 & 10 & 3.10 & 3.32 & 3.26 & 10.1641 & 3.22667 \\
1500 & 1.50 & 15 & 12 & 4.55 & 3.29 & 3.15 & 10.9426 & 3.66333 \\
2000 & 1.00 & 10 & 12 & 4.87 & 4.28 & 4.39 & 13.0498 & 4.51333 \\
2000 & 1.25 & 15 & 8 & 3.81 & 3.72 & 3.97 & 11.6622 & 3.83333 \\
2000 & 1.50 & 5 & 10 & 6.94 & 6.97 & 8.25 & 17.2863 & 7.38667 \\
2500 & 1.00 & 15 & 10 & 4.09 & 6.86 & 6.96 & 14.6992 & 5.97000 \\
2500 & 1.25 & 5 & 12 & 5.28 & 5.61 & 5.92 & 14.9405 & 5.60333 \\
2500 & 1.50 & 10 & 8 & 8.30 & 8.13 & 9.69 & 18.7187 & 8.70667 \\
\hline
\end{tabular}

Table (5) The main effects of $\mathrm{S} / \mathrm{N}$ ratio values of all levels for tensile-shear strength

\begin{tabular}{lcccc}
\hline Level & $\begin{array}{c}\text { Rotational speed } \\
(\mathbf{r p m})\end{array}$ & $\begin{array}{c}\text { Plunge depth } \\
(\mathbf{m m})\end{array}$ & $\begin{array}{c}\text { Plunge rate } \\
(\mathbf{m m} / \mathbf{m i n})\end{array}$ & $\begin{array}{c}\text { Dwell time } \\
(\mathbf{s e c})\end{array}$ \\
\hline 1 & 9.76 & 11.98 & 13.47 & 12.86 \\
2 & 13.99 & 12.26 & 12.44 & 14.05 \\
3 & 16.12 & 15.65 & 12.44 & 12.98 \\
Delta & 6.34 & 3.67 & 1.54 & 1.19 \\
\hline
\end{tabular}

Table (6) The main effects of average mean and of all levels for tensile-shear strength

\begin{tabular}{lcccc}
\hline Level & $\begin{array}{c}\text { Rotational speed } \\
(\mathbf{r p m})\end{array}$ & $\begin{array}{c}\text { Plunge depth } \\
(\mathbf{m m})\end{array}$ & $\begin{array}{c}\text { Plunge rate } \\
(\mathbf{m m} / \mathbf{m i n})\end{array}$ & $\begin{array}{c}\text { Dwell time } \\
(\mathbf{s e c})\end{array}$ \\
\hline 1 & 3.15 & 4.35 & 5.19 & 5.04 \\
2 & 5.24 & 4.22 & 5.48 & 5.53 \\
3 & 6.76 & 6.59 & 4.49 & 4.59 \\
Delta & 3.61 & 3.36 & 0.99 & .0 .93 \\
\hline
\end{tabular}

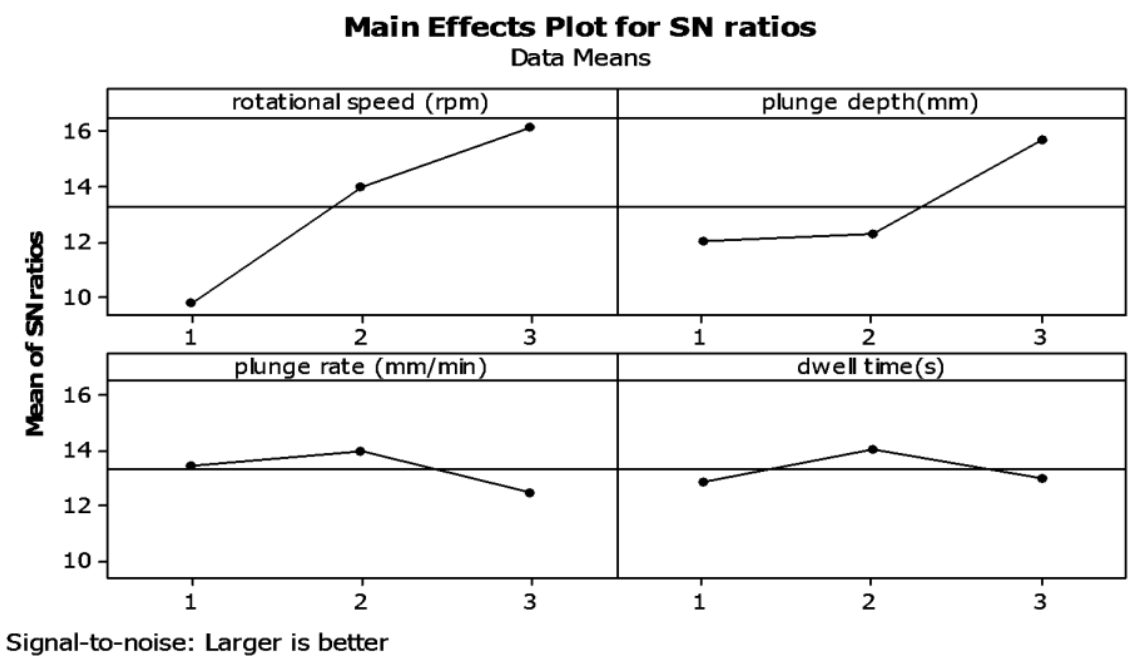

Fig (3) Main effects of $\mathrm{S} / \mathrm{N}$ ratios for tensile-shear strength 
Main Effects Plot for Means

Data Means

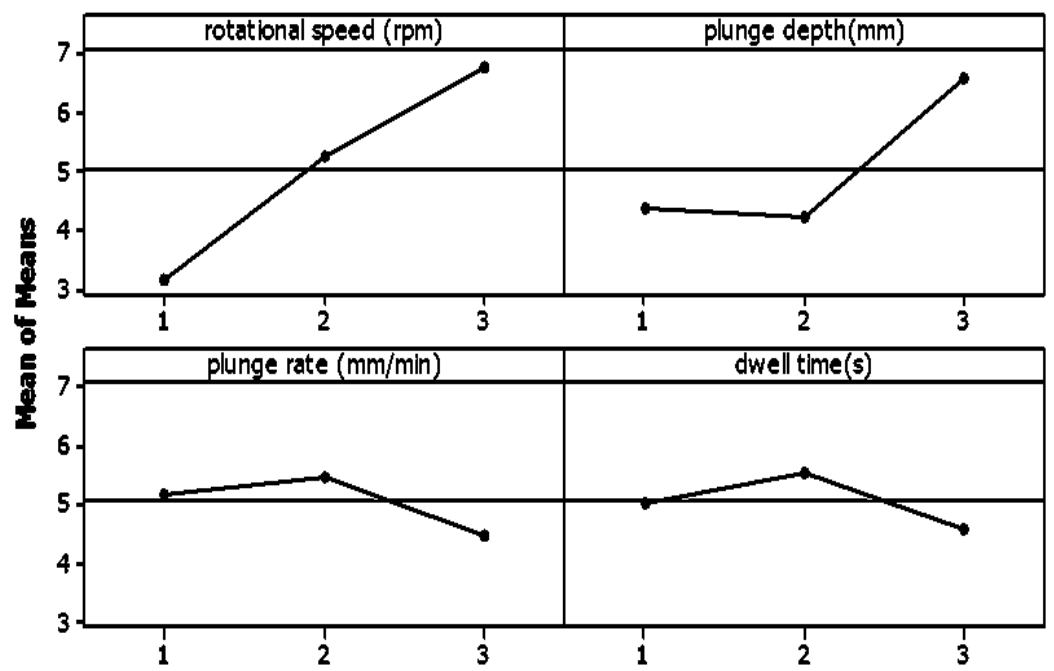

Fig (4) Main effects of means for tensile-shear strength

The ANOVA results for tensile-shear strength of $\mathrm{S} / \mathrm{N}$ ratio and mean are given in Tables 7 and 8 , respectively. The percentage of contribution is the portion of the total variation observed in the experiment attributed to each significant factors and/or interaction which is reflected. The percentage of contribution is a function of the sum of squares for each significant item; it indicates the relative power of a factor to reduce the variation. If the factor levels are controlled precisely, then the total variation could be reduced by the amount indicated by the percentage of contribution. The percentage of contribution of the rotational speed, welding speed, plunge depth, plunge rate and dwell time is shown in Fig (5). It is clear the plunge depth is the most FSSW process parameter that affects the tensile-shear characteristics of AA2024-T6 joints. The rotational speed showed a contribution of $66.69 \%$ of the overall response.

Table (7) ANOVA for S/N, using Adjusted SS for tensile-shear tests

\begin{tabular}{lccccc}
\hline source & DF & Seq SS & Adj SS & Adj MS & Contribution (P, \%) \\
\hline rotational speed & 2 & 62.818 & 62.818 & 31.409 & 66.69427103 \\
plunge depth & 2 & 25.068 & 25.068 & 12.534 & 26.61485540 \\
plunge rate & 2 & 3.711 & 3.711 & 1.856 & 3.939992356 \\
dwell time & 2 & 2.591 & 2.591 & 1.295 & 2.750881216 \\
error & 0 & $*$ & $*$ & $*$ & 100 \\
Total & 8 & 94.188 & & & \\
\hline
\end{tabular}

$\mathrm{DF}=$ Degrees of freedom, Seq SS=Sequential sum of squares, Adj SS=Adjusted sum of square, Adj $\mathrm{MS}=$ Adjusted mean square.

Table (8) ANOVA for mean, using Adjusted SS for tensile-shear tests

\begin{tabular}{lccccc}
\hline source & DF & Seq SS & Adj SS & Adj MS & Contribution (P, \%) \\
\hline rotational speed & 2 & 19.6904 & 19.6904 & 9.8452 & 59.36851754 \\
plunge depth & 2 & 10.6049 & 10.6049 & 5.3025 & 31.97482995 \\
plunge rate & 2 & 1.5601 & 1,5601 & 0.7800 & 4.703856915 \\
dwell time & 2 & 1.3110 & 1.3110 & 0.6555 & 3.95279560 \\
error & 0 & $*$ & & & \\
Total & 8 & 33.1664 & & & 100 \\
\hline
\end{tabular}




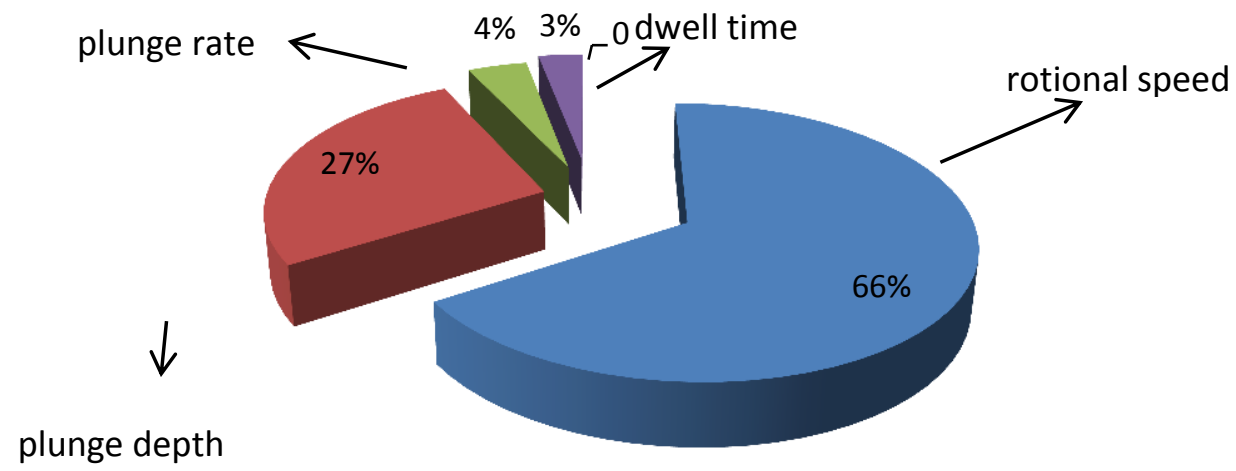

Fig (5) Contribution of each factor on the performance statistics (Influential effects based on percentage distributions)

\section{Conclusions}

Based the aforementioned results, the following conclusions can be concluded:

1. The FSSW process parameters are optimized to maximize the tensile-shear strength of AA2024-T6 lap joints. The optimum levels of the rotational speed, plunge depth, plunge rate and dwell time are found to be $2500 \mathrm{rpm}, 1.5$ $\mathrm{mm}, 10 \mathrm{~mm} / \mathrm{min}$ and 10 seconds, respectively.

2. The rotational speed can be considered the most influential FSSW process parameter on the tensile-shear strength. It showed a percentage of contribution of $66.69 \%$ of the overall response.

3. The plunge depth, plunge rate and dwell time FSSW process parameters showed percentage of contribution of $23 \%, 4 \%$ and $3 \%$, respectively, of the overall response.

\section{Acknowledgment}

The authors are thankful to Benha UniversityFaculty of Engineering at Shoubra for providing facilities for carrying out this work.

\section{References}

[1] Joseph R. Davis, "Aluminum and Aluminum Alloys", ASM International, 1993.

[2] R.S. Mishra and Z.Y. Ma. "Friction Stir Welding and Processing", Mater. Sci. Eng. R, 50, pp. 1-78.2005
[3] G. Pieta, J. dos Santos, T. R. Strohaecker, T. Clarke. "Optimization of Friction Spot Welding Process Parameters for AA2198-T8 Sheets". Materials and Manufacturing Processes, 29(8), pp. 37-41, 2014.

[4] Saleh Alhetaa, Sayed Zayanb, Tamer Mahmoud, Attia Gomaad "Optimization of Friction Stir Spot Welding Process Parameters for AA6061-T4 Aluminum Alloy Plates". American Scientific Research Journal for Engineering, Technology, and Sciences (ASRJETS), 20(1), pp. 244-253, 2016.

[5] R. Padmanaban, R. Vaira Vignesh, M. Arivarasu, Karthick K. P. and A. Abirama Sundar" Process Parameters Effect on the Strength of Friction Stir Spot Welded AA6061", ARPN Journal of Engineering and Applied Sciences, 11(9), pp. 1819-6608, 2016.

[6] Yahya Bozkurt, Mustafa Kemal Bilici, "Application of Taguchi approach to optimize of FSSW parameters on joint properties of dissimilar AA2024-T3 and AA5754-H22 aluminum alloys", Materials and Design, 51, pp. 513-521, 2013.

[7] Mumin Tutar, Hakan Aydin, Celalettin Yuce, Nurettin Yavuz, Ali Bayram, "The optimisation of process parameters for friction stir spotweldedAA3003-H12 aluminium alloy using a Taguchi orthogonal array", Materials and Design, 63, pp.789-797, 2014.

[8] Y.Rostamiyan, A. Seidanloo, H. Sohrabpoor, R. Teimouri, "Experimental studies on ultrasonically assisted friction stir spot welding of AA6061", Materials and Design, 15(2), pp. 1644-9665, 2014. 